\title{
Níveis de cromo orgânico na dieta de codornas japonesas mantidas em estresse por calor na fase de postura ${ }^{1}$
}

\author{
Marcelle Santana de Araújo ${ }^{2}$, Sergio Luiz de Toledo Barreto ${ }^{3}$, Juarez Lopes Donzele ${ }^{3}$, \\ Rita Flávia Miranda de Oliveira $^{3}$, Regina Tie Umigi ${ }^{4}$, Will Pereira de Oliveiraa ${ }^{5}$, Eric Márcio \\ Balbino $^{5}$, Ana Paula de Assis ${ }^{5}$, Gustavo Vaz Corrêa Maia ${ }^{5}$
}

\author{
1 Parte da tese de Mestrado da primeira autora. \\ ${ }^{2}$ Mestranda do Depto. de Zootecnia da UFV - Av. P.H. Holfs, s/n - CEP: 36570-000 -Viçosa-MG. \\ ${ }^{3} \mathrm{UFV} / \mathrm{DZO}$. \\ ${ }^{4}$ Mestranda do Depto. de Zootecnia da UFV. \\ 5 Graduando do Depto. de Zootecnia da UFV.
}

RESUMO - O experimento foi conduzido com objetivo de avaliar o efeito da adição de cromo orgânico (Cr) na alimentação de codornas japonesas na fase inicial de postura mantidas em estresse por calor. Seiscentas codornas com 63 dias de idade e peso inicial de 158,6 g foram mantidas em ambiente de alta temperatura (32 ${ }^{\circ} \mathrm{C}$ ) e alimentadas com dietas à base de milho e farelo de soja suplementadas com $\mathrm{Cr}$ (cromo-metionina) em substituição ao inerte $(0,500,1.000,1.500$ e $2.000 \mathrm{ppb}$ ). O delineamento utilizado foi o inteiramente casualizado, com cinco tratamentos, 12 repetições e dez aves por unidade experimental, adotando-se o teste de Willians a 5\% de significância (a) para análise de cada variável: produção de ovos (taxa de postura/ave/dia; taxa de postura por ave alojada; taxa de postura de ovos comercializáveis; peso de ovo); consumo de ração; conversão alimentar (por $\mathrm{kg}$ e por dúzia de ovos); e massa de ovos. O fornecimento de cromo orgânico no nível de 500 ppb promoveu melhora na produção de ovos comercializáveis e, no nível de 2.000 ppb, resultou em aumento no consumo de ração. As demais variáveis não foram influenciadas pelos níveis de $\mathrm{Cr}$ na dieta. O nível de 500 ppb de Cr na dieta é indicado para aumento da produção de ovos comercializáveis de codornas japonesas em fase de postura mantidas em estresse por calor.

Palavras-chave: Coturnix coturnix japonica, minerais, produção, temperatura

\section{Levels of organic chromium on diet of laying Japanese quails under heat stress}

\begin{abstract}
The objective was to evaluate the effects of the addition of organic chromium in the diet of Japanese quails in the initial fase of laying, under heat stress. Six hundred quails averaging 63 days old and initial body weight of $158.60 \mathrm{~g}$ on high temperature environment $\left(32^{\circ} \mathrm{C}\right)$ were used. Diets were based on corn and soybean meal, and supplemented with five levels of chromium $(0,500,1,000,1,500$, and 2,000 ppb), from chromium-methionine, in replacement with innert material. The experimental design was completely randomized, with 12 experimental units per treatment and ten birds in each experimental unit. The least significant level for $\mathrm{Cr}$ inclusion in the diet was obtained using the Willians test, at 5\% significance level, on the following variables: egg production (total egg production, egg production by lodged bird and commercial egg production by lodged bird, egg weight), feed intake, feed conversion (by $\mathrm{kg}$ of egg and by dozen of egg) and egg mass. The level of $500 \mathrm{ppb}$ increased the egg commercial production by lodged bird. Feed intake increased at $2000 \mathrm{ppb}$ Cr. Other variables were not influenced by the different supplemental $\mathrm{Cr}$ levels. The results allow to conclude that $500 \mathrm{ppb}$ of supplemental chromium, from chromiummethionine, was able to improve the egg commercial production of laying Japanese quail under heat stress.
\end{abstract}

Key Words: Coturnix coturnix japonica, minerals, production, temperature

\section{Introdução}

A criação de codornas para fins de produção destaca-se na avicultura como um produto alternativo (carne e ovos) de alta qualidade e de fácil manejo. Fatores como pequena exigência de espaço, baixo consumo de ração, pequeno intervalo de geração, maturidade sexual precoce e alta taxa de crescimento inicial favorecem a caracterização da codorna como uma ave excelente, tanto para instituições de pesquisa como para produção em diferentes regiões. Entretanto, em 
climas tropicais e subtropicais como no Brasil, a radiação solar intensa e a elevada temperatura e umidade relativa do ar no verão geram desconforto térmico quase permanente às aves, prejudicando seu desempenho produtivo e tornando-se os principais problemas que afetam a exploração avícola (Tinôco, 1994). Na zona termoneutra, no entanto, as aves despendem pouca energia para manter sua homeotermia, de modo que praticamente toda energia assimilada da dieta é destinada aos processos produtivos.

Considerando que algumas variáveis ambientais, como temperatura e umidade relativa do ar, interferem na produção e no bem-estar das aves, é necessário que sejam monitoradas e bem manejadas, a fim de maximizar a produção. Altas temperaturas afetam o desempenho dos animais reduzindo o consumo de ração e o de nutrientes essenciais às funções fisiológicas, como os minerais.

Os minerais representam de 3 a $4 \%$ do peso vivo das aves, sendo considerados elementos essenciais para uma boa nutrição, além de exercerem funções variadas no organismo, como a participação nas reações bioquímicas, por meio da ativação de sistemas enzimáticos, e nos processos de absorção e transporte de nutrientes. Em animais submetidos a situações de estresse por calor, ocorre excessiva excreção urinária de minerais (Lien et al., 1999), o que pode alterar as exigências nutricionais desses nutrientes. Entre os minerais mais estudados em ambientes de estresse, destaca-se o cromo $(\mathrm{Cr})$, requerido para o correto metabolismo de carboidratos e lipídeos em nível molecular (Vincent, 2001).

A manipulação de dietas com nutrientes funcionais tem sido alvo de várias pesquisas com o propósito de melhorar o desempenho de aves durante os meses quentes do ano. Quando utilizado em dietas para aves, o cromo mostra-se eficaz em reduzir os efeitos negativos causados pelo estresse por calor, mantendo elevada produtividade e qualidade dos ovos.

Visando à melhoria na produtividade da espécie Coturnix coturnix japonica, avaliou-se o efeito da suplementação de diferentes níveis de cromo na produção de ovos de codornas mantidas sob estresse por calor.

\section{Material e Métodos}

Foram utilizadas 600 codornas japonesas alojadas em uma sala do Departamento de Zootecnia do Centro de Ciências Agrárias da Universidade Federal de Viçosa - MG. Cada bateria foi composta de cinco gaiolas (cinco andares) de arame galvanizado, cada uma com três unidades experimentais e com dimensões de 96 x 37 x 16 cm (largura x profundidade $\mathrm{x}$ altura). Em cada unidade experimental, foram alojadas dez aves. Sob o piso das gaiolas, foi colocada uma bandeja de chapa metálica galvanizada encapada com plástico preto para recolhimento das excretas. As gaiolas foram equipadas com comedouros de chapa metálica galvanizada e bebedouros de cano de PVC - poli (cloreto de vinila), ambos percorrendo toda a extensão da gaiola, sendo o comedouro posicionado na parte frontal e o bebedouro na parte posterior. Cada comedouro foi equipado com divisórias em madeira, coincidindo com a largura de cada unidade experimental.

A partir dos 40 dias de idade das aves, a iluminação do ambiente foi feita por quatro lâmpadas fluorescentes controladas por um timer, com fornecimento de 14 horas de luz artificial por dia e aumentos semanais de uma hora até atingir fornecimento de 17 horas de luz por dia.

As aves foram alimentadas com a mesma dieta fornecida nas fases de cria e recria (24\% de PB e 2.900 kcal de EM) até atingirem taxa de postura de 10\% (60 ovos), o que ocorreu aos 50 dias de idade, quando se iniciou o fornecimento gradual da dieta de postura (20\% de PB e $2.900 \mathrm{kcal}$ de EM). Inicialmente, misturou-se $1 / 3$ da dieta de postura; depois de três dias, aumentou-se para 2/3 e, após quatro dias, distribuiu-se somente a dieta de postura.

Aos 63 dias de idade e com produção média de 81,3\%, as aves foram transferidas para as salas climatizadas do Laboratório de Bioclimatologia, com dimensões de 5,70 x 2,85 m (Sala 1) e 5,40 x 3,90 m (Sala 2), para início do período experimental propriamente dito.

O delineamento experimental utilizado foi o inteiramente casualizado, constituído de cinco tratamentos (níveis de cromo), 12 repetições e dez aves por unidade experimental.

As dietas experimentais (isoenergéticas, isoprotéicas e isoaminoacídicas) foram formuladas à base de milho e farelo de soja, considerando as exigências nutricionais preconizadas pelo NRC (1994), exceto para lisina e cálcio, as quais seguiram as recomendações de Pinto et al. (2003) e Pereira (2004), respectivamente.

Os níveis de $\mathrm{Cr}$ das dietas foram obtidos pela substituição do inerte (areia) por cromo-metionina, resultando nos níveis de 0, 500, 1.000, 1.500 e 2.000 ppb de Cr (Tabela 1).

As dietas foram fornecidas duas vezes por dia (8 e 16h) e a água foi disponibilizada à vontade e renovada três vezes por dia (7h30, $13 \mathrm{~h} 30$ e 20h). Os ovos foram recolhidos e contabilizados uma vez por dia. Após o fornecimento da dieta, procedia-se à lavagem dos bebedouros e à limpeza das bandejas de excretas e dos aparadores de ovos.

A temperatura e a umidade relativa do ar no interior das salas climatizadas foram mantidas constantes $\left(\mathrm{em} 32^{\circ} \mathrm{Ce}\right.$ 
Tabela 1 - Composição percentual e nutricional das dietas experimentais

Table 1 - Percentage composition and calculated nutritional values of experimental diets

\begin{tabular}{|c|c|c|c|c|c|}
\hline \multirow[t]{2}{*}{$\begin{array}{l}\text { Ingrediente } \\
\text { Ingredient }\end{array}$} & \multicolumn{5}{|c|}{$\begin{array}{l}\text { Nível de cromo (ppb) } \\
\text { Chromium level ( } p p b)\end{array}$} \\
\hline & 0 & 500 & 1.000 & 1.500 & 2.000 \\
\hline Milho (Corn) & 54,544 & 54,544 & 54,544 & 54,544 & 54,544 \\
\hline Farelo de soja (45\%) (Soybean meal) & 32,162 & 32,162 & 32,162 & 32,162 & 32,162 \\
\hline Óleo de soja (Soybean oil) & 2,942 & 2,942 & 2,942 & 2,942 & 2,942 \\
\hline Calcário (Limestone) & 7,167 & 7,167 & 7,167 & 7,167 & 7,167 \\
\hline Fosfato bicálcico (Dicalcium phosphate) & 1,325 & 1,325 & 1,325 & 1,325 & 1,325 \\
\hline Sal (Salt) & 0,281 & 0,281 & 0,281 & 0,281 & 0,281 \\
\hline DL-metionina (99\%) (DL-methionine) & 0,574 & 0,574 & 0,574 & 0,574 & 0,574 \\
\hline L-lisina $\mathrm{HCl}(78 \%)$ (L-lysine) & 0,247 & 0,247 & 0,247 & 0,247 & 0,247 \\
\hline L-treonina (L-threonine) & 0,164 & 0,164 & 0,164 & 0,164 & 0,164 \\
\hline L-triptofano (L-tryptophan) & 0,084 & 0,084 & 0,084 & 0,084 & 0,084 \\
\hline Cloreto de colina $(60 \%)$ (Choline chloride) & 0,040 & 0,040 & 0,040 & 0,040 & 0,040 \\
\hline Mistura mineral $^{1}$ (Mineral mix) & 0,050 & 0,050 & 0,050 & 0,050 & 0,050 \\
\hline Mistura vitamínica $^{2}$ (Vitamin mix) & 0,100 & 0,100 & 0,100 & 0,100 & 0,100 \\
\hline Antioxidante ${ }^{3}$ (Antioxidant) & 0,010 & 0,010 & 0,010 & 0,010 & 0,010 \\
\hline Surmax $100^{4}$ & 0,010 & 0,010 & 0,010 & 0,010 & 0,010 \\
\hline Cromo-metionina $^{5}$ (Chromium methionine) & 0,000 & 0,050 & 0,100 & 0,150 & 0,200 \\
\hline Inerte $^{6}$ (Innert) & 0,300 & 0,250 & 0,200 & 0,150 & 0,100 \\
\hline \multicolumn{6}{|l|}{$\begin{array}{l}\text { Composição calculada } \\
\text { Calculated composition }\end{array}$} \\
\hline $\mathrm{PB}(C P), \%$ & 20,000 & 20,000 & 20,000 & 20,000 & 20,000 \\
\hline $\mathrm{EM}(M E)(\mathrm{kcal} / \mathrm{kg})$ & 2.900 & 2.900 & 2.900 & 2.900 & 2.900 \\
\hline $\mathrm{Cr}(\mu \mathrm{g} / \mathrm{kg})$ & 0,0 & 0,5 & 1,0 & 1,5 & 2,0 \\
\hline $\mathrm{Ca}(\%)$ & 3,200 & 3,200 & 3,200 & 3,200 & 3,200 \\
\hline $\mathrm{Na}(\%)$ (Sodium) & 0,150 & 0,150 & 0,150 & 0,150 & 0,150 \\
\hline P disponível (\%) (Available P) & 0,350 & 0,350 & 0,350 & 0,350 & 0,350 \\
\hline Metionina digestível (\%) (Available methionine) & 0,845 & 0,845 & 0,845 & 0,845 & 0,845 \\
\hline Metionina + cistina digestíveis (\%) (Available methionine + cystine) & 1,106 & 1,106 & 1,106 & 1,106 & 1,106 \\
\hline Lisina total $(\%)$ (Total lysine) & 1,223 & 1,223 & 1,223 & 1,223 & 1,223 \\
\hline Lisina digestível (\%) (Available lysine) & 1,117 & 1,117 & 1,117 & 1,117 & 1,117 \\
\hline Treonina digestível (\%) (Available threonine) & 0,815 & 0,815 & 0,815 & 0,815 & 0,815 \\
\hline Triptofano digestível (\%) (Available thyptophan) & 0,301 & 0,301 & 0,301 & 0,301 & 0,301 \\
\hline
\end{tabular}

$65 \%$, respectivamente) e as leituras dos termômetros de bulbo seco e úmido e de globo negro foram feitas duas vezes ao dia, às 8 e 16h. Posteriormente, os dados foram convertidos em Índice de Temperatura de Globo e Umidade (ITGU), segundo Buffington et al. (1981).

Foram avaliados a produção de ovos, o consumo de ração, a conversão alimentar, o peso médio dos ovos e a massa de ovos.

Para o cálculo da análise de variância, utilizou-se o programa SAEG - Sistema para Análises Estatísticas e Genéticas (UFV, 1999) e aplicou-se o teste de Willians (Willians, 1971) às médias obtidas, a 5\% de probabilidade, no caso de efeito significativo de tratamento, para determinação do nível mínimo de resposta significativa da suplementação de Cr na dieta.

\section{Resultados e Discussão}

Durante todo o período experimental, a temperatura do $\operatorname{ar}\left(31,8 \pm 0,35^{\circ} \mathrm{C}\right)$, a umidade relativa $(64,9 \pm 2,20 \%)$ e o índice de temperatura de globo e umidade (ITGU) $(82,2 \pm 0,40)$ foram mantidos constantes no interior das salas.

Como demonstrado na Tabela 2 , à exceção do consumo de alimento $(\mathrm{CR})$, que aumentou $(\mathrm{P}<0,05)$ quando utilizado o nível de 2.000 ppb de $\mathrm{Cr}$ e da taxa de postura de ovos comercializáveis (TPOC), que aumentou $(\mathrm{P}<0,05)$ quando utilizada a dieta com 500 ppb de $\mathrm{Cr}$, em comparação ao grupo sem suplementação de $\mathrm{Cr}$, os demais parâmetros avaliados não foram influenciados $(\mathrm{P}>0,05)$ pelos níveis de $\mathrm{Cr}$ da dieta.

Os resultados obtidos neste estudo para o consumo de alimento estão de acordo com os encontrados por Sahin et 
Tabela 2 - Valores médios de consumo de ração (CR), produção total de ovos ( $\mathrm{g}$ de ovos/ave/dia (TP), produção de ovos comercializáveis (TPOC), produção de ovos por ave alojada (TPAA), peso de ovo (PO), massa de ovos/ave/dia (MOAD), conversão alimentar por massa de ovos (CA) e conversão alimentar por dúzia de ovos (CAD)

Table 2 - Average values of feed intake (FI), total egg production (TEP), commercial egg production (CEP), egg production by lodjed bird (EPL), egg weight $(W E)$, egg mass (EM), feed conversion by egg mass ( $\mathrm{kg})$ (FCE) and feed conversion by dozen of egg (FCD)

\begin{tabular}{|c|c|c|c|c|c|c|c|}
\hline & \multicolumn{5}{|c|}{$\begin{array}{c}\text { Nível de cromo (ppb) } \\
\text { Chromium level }\end{array}$} & \multirow[t]{2}{*}{$\mathrm{CV}^{1}$} & \multirow[t]{2}{*}{$\mathrm{NMRS}^{2}$} \\
\hline & 0 & 500 & 1.000 & 1.500 & 2.000 & & \\
\hline $\mathrm{CR}_{(F I)}(\mathrm{g})$ & 19,93 & 19,86 & 20,16 & 20,35 & 20,62 & 3,6 & 2000 \\
\hline $\mathrm{TP}(T E P)(\%)$ & 82,29 & 85,02 & 84,59 & 84,16 & 85,07 & 4,7 & - \\
\hline TPOC (CEP) $(\%)$ & 80,23 & 83,62 & 83,50 & 82,65 & 83,52 & 4,7 & 500 \\
\hline TPAA $(E P L)(\%)$ & 81,50 & 83,27 & 83,29 & 83,65 & 83,52 & 5,0 & - \\
\hline $\mathrm{PO}(W E) \quad(\mathrm{g})$ & 10,77 & 10,77 & 10,88 & 10,81 & 10,79 & 2,4 & - \\
\hline $\operatorname{MOAD}(E M)(\mathrm{g})$ & 8,856 & 9,134 & 9,199 & 9,099 & 9,250 & 5,6 & - \\
\hline $\mathrm{CA}(F C E)$ & 2,255 & 2,176 & 2,193 & 2,242 & 2,233 & 4,1 & - \\
\hline $\mathrm{CAD}(F C D)$ & 0,291 & 0,280 & 0,286 & 0,291 & 0,291 & 4,2 & - \\
\hline
\end{tabular}

1 Coeficiente de variação (\%) (Coeficient of variation).

2 Nível mínimo a partir do qual são verificadas respostas significativas pelo teste de Willians $(\mathrm{P}<0,05)($ The least significant level for Cr inclusion on diets, using the Willians'test, considering $5 \%$ significance level).

al. (2002a), que, avaliando níveis de cromo-picolinato (CrPi) em dietas para codornas japonesas em postura mantidas em ambiente de alta temperatura $\left(32,5^{\circ} \mathrm{C}\right)$, observaram que a suplementação de $\mathrm{Cr}$ à dieta resultou em aumento do $\mathrm{CR}$ das aves. Em estudos conduzidos com galinhas poedeiras sob estresse por frio (Sahin et al., 2001) e com frangos de corte em ambiente termoneutro (Lien et al., 1999) e sob estresse por calor (Sahin et al., 2002b e 2003), foi observado aumento do consumo em resposta à suplementação de $\mathrm{Cr}$ às dietas.

$\mathrm{O}$ aumento de 4,22\% ( $\mathrm{P}<0,05)$ na produção de ovos comercializáveis (TPOC) com a inclusão de 500 ppb de $\mathrm{Cr}$ orgânico à dieta ocorreu de forma independente do consumo de alimento (CR), visto que esse parâmetro não variou entre o grupo sem suplementação e com inclusão de 500 ppb de $\mathrm{Cr}$ à dieta. Esse resultado evidenciou que o $\mathrm{Cr}$ tem influência positiva na formação da casca do ovo de codornas japonesas mantidas em ambiente de alta temperatura, pois melhorou a produção de ovos comercializáveis, reduzindo o número de ovos com casca mole, de ovos sem casca e de ovos quebradiços e, conseqüentemente, diminuindo a perda total de ovos (Tabela 3 ).

Uma vez que a qualidade da casca do ovo está diretamente relacionada à sua concentração de cálcio, pode-se deduzir que o $\mathrm{Cr}$ influenciou na deposição de cálcio na casca do ovo das aves. No entanto, não foi possível comprovar esta hipótese, pois, na literatura consultada, não foram encontrados dados sobre a influência da inclusão de Cr na dieta sobre a qualidade da casca do ovo de codornas japonesas ou de galinhas poedeiras.

A taxa de postura (TP) não foi influenciada $(\mathrm{P}>0,05)$ pelos níveis de $\mathrm{Cr}$ na dieta, porém, houve melhora de 3,3\% na produção média de ovos/ave/dia com a inclusão de 500 ppb de $\mathrm{Cr}$ em comparação à dieta sem adição de Cr. Esse resultado difere do encontrado por Sahin et al. 2002a, que, em estudo com codornas japonesas em postura mantidas em ambientes de alta temperatura $\left(32,5^{\circ} \mathrm{C}\right)$, constataram aumento na produção de ovos quando a dieta foi suplementada com 1.200 ppb de CrPi. Em estudos realizados com galinhas poedeiras sob estresse por frio, Sahin et al. (2001, 2002c) comprovaram efeitos positivos da inclusão, respectivamente, de 200 e 400 ppb sobre a taxa de postura das aves.

O nível de $\mathrm{Cr}$ da dieta não influenciou $(\mathrm{P}>0,05)$ o peso de ovo (PO). De modo similar, ao adicionarem $10.000 \mathrm{ppb}$ de $\mathrm{Cr}(\mathrm{CrCl3} .6 \mathrm{H} 2 \mathrm{O})$ na dieta de galinhas poedeiras, Jensen \& Maurice (1980) não observaram variação significativa no peso dos ovo produzidos. Os resultados de peso obtidos neste estudo diferem, no entanto, dos registrados por Sahin et al. (2002a), que notaram aumento $(\mathrm{P}<0,05)$ no peso do ovo com a inclusão de 1.200 ppb de $\mathrm{Cr}$ na dieta de codornas japonesas mantidas sob estresse por calor $\left(32,5^{\circ} \mathrm{C}\right)$. Sahin et al. 2002c, em experimento com poedeiras sob estresse por baixas temperaturas $\left(6,8^{\circ} \mathrm{C}\right)$, também verificaram que a inclusão de $400 \mathrm{ppb}$ de $\mathrm{Cr}$ promoveu aumento $(\mathrm{P}<0,05)$ no peso dos ovos em relação aos do grupo controle.

Não houve efeito $(\mathrm{P}>0,05)$ dos níveis de $\mathrm{Cr}$ da dieta sobre a massa de ovos/ave/dia (MOAD), embora a inclusão de $\mathrm{Cr}$ às dietas tenha ocasionado aumento médio de $3,1 \%$ neste parâmetro nas aves alimentadas com a dieta com 500 ppb de $\mathrm{Cr}$ em comparação às do grupo controle. A massa de ovos/ave/dia também tem sido pouco pesquisada e com pequena quantidade de dados publicados, principalmente na literatura internacional. Neste estudo, a massa de ovos foi de 9,12 g, valor próximo ao obtido por Pereira (2004), de 9,37 g. Entretanto, os animais estavam sob estresse térmico, comprovando que codornas japonesas em fase de postura 
Tabela 3 - Números de ovos com casca mole, sem casca e quebrados e perda total com a suplementação de $\mathrm{Cr}$ às dietas experimentais

Table 3 - $\quad$ Number of eggs with soft eggshell, without eggshell, broken eggshell and total egg loss for different Crlevels in comparison with the control diet

\begin{tabular}{|c|c|c|c|c|c|}
\hline & \multicolumn{5}{|c|}{$\begin{array}{c}\text { Nível de cromo (ppb) } \\
\text { Cr level }\end{array}$} \\
\hline & 0 & 500 & 1.000 & 1.500 & 2.000 \\
\hline $\begin{array}{l}\text { Casca mole }(\%) \\
\text { Soft eggshell }\end{array}$ & 0,50 & 0,25 & 0,15 & 0,27 & 0,37 \\
\hline $\begin{array}{l}\text { Sem casca }(\%) \\
\text { Without eggshell }\end{array}$ & 0,54 & 0,39 & 0,26 & 0,54 & 0,54 \\
\hline $\begin{array}{l}\text { Quebradiços (\%) } \\
\text { Broken eggshell }\end{array}$ & 1,31 & 0,90 & 0,66 & 1,03 & 0,93 \\
\hline $\begin{array}{l}\text { Perda total }(\%) \\
\text { Total egg loss }\end{array}$ & 2,35 & 1,54 & 1,07 & 1,83 & 1,84 \\
\hline
\end{tabular}

são capazes de suportar os efeitos negativos ocasionados pela alta temperatura. Pinto et al. (2003) obtiveram massa de ovos inferior, de 9,04 g, ao testarem níveis de lisina para codornas japonesas sob conforto térmico.

A conversão alimentar por massa de ovos (CA) não foi influenciada $(\mathrm{P}<0,05)$ pela inclusão de $\mathrm{Cr}$ nas dietas, apesar da melhora de $3,5 \%$ com a utilização de 500 ppb de Cr em comparação àquela sem suplementação desse mineral. Esse resultado difere do obtido por Sahin et al. (2002a), que notaram melhora significativa na CA de codornas japonesas mantidas em ambiente de alta temperatura $\left(32,5^{\circ} \mathrm{C}\right)$ alimentadas com dietas suplementadas com 1.200 ppb de Cr. Em estudo com galinhas poedeiras sob estresse por frio $\left(6,9^{\circ} \mathrm{C}\right)$, Sahin et al. (2001) também observaram melhora na conversão alimentar das aves quando a dieta foi suplementada com 400 ppb de $\mathrm{Cr}$ (CrPi).

Do mesmo modo que a conversão alimentar por massa de ovos, a conversão alimentar por dúzia de ovos (CAD) também não foi influenciada $(\mathrm{P}>0,05)$ pelos níveis de inclusão de Cr na dieta, apesar da melhora de 3,8\% com a inclusão de $500 \mathrm{ppb}$ de $\mathrm{Cr}$ nas dietas.

\section{Conclusões}

O nível de 500 ppb de cromo na dieta, correspondente a um consumo de 9,93 $\mu \mathrm{g}$ de cromo/ave/dia, é indicado para aumento da produção de ovos comercializáveis de codornas japonesas em fase de postura mantidas em ambiente de estresse por calor.

\section{Literatura Citada}

BUFFINGTON, D.E.; COLAZZO-AROCHO, A.; CANTON, G.H. et al. Black globe-humidity index (BGHI) as comfort equation for dairy cows. Transaction of the ASAE, v.24, p.711-714, 1981.

JENSEN, L.S.; MAURICE, D.V. Dietary chromium and interior egg quality. Poultry Science, v.59, p.341-346, 1980.

LIEN, T.H.; HOMG, Y.M.; YANG, K.H. Performance, serum characteristics, carcass traits and lipid metabolism of broilers as affect by supplement of chromium picolinate. British Poultry Science, v.40, p.357-363, 1999.

NATIONAL RESERCH COUNCIL - NRC. Nutrient requirements of poultry. 9.ed. Washington: National Academy of Sciences, 1994. $155 \mathrm{p}$.

PEREIRA, C.A.; BARRETO, S.L.T.; ROSTAGNO, H.S. et al. Desempenho de codornas japonesas alimentadas com dietas contendo diferentes níveis de cálcio durante o pico de postura. In: REUNIÃO ANUAL DA SOCIEDADE BRASILEIRA DE ZOotecnia, 41., 2004, Campo Grande. Anais... Campo Grande: Sociedade Brasileira de Zootecnia [2004]. (CD-ROM).

PINTO, R.; FERREIRA A.S.; DONZELE, J.L. et al. Exigências de lisina para codornas japonesas em postura. Revista Brasileira de Zootecnia, v.32, n.5, p.1182-1189, 2003.

SAHIN, K.; KÜÇÜK, O.; SAHIN, N. Effects of dietary chromium picolinate supplementation on performance and plasma concentrations of insulin and corticosterone in laying hens under low ambient temperature. Journal of Animal Physiology and Nutrition, v.85, p.142-147, 2001

SAHIN, K.; SAHIN, N. Effects of chromium picolinate and acid ascorbic dietary supplementation on nitrogen and mineral excretion of laying hens reared in a low ambient temperature $\left(7^{\circ} \mathrm{C}\right)$. Acta Veterinaria Brno, v.71, p.183-189, 2002a.

SAHIN, K.; ONDERCI, M.; SAHIN, N. et al. Effects of dietary chromium picolinate and ascorbic acid supplementation on egg production, egg quality and some blood metabolites of laying hens reared under low ambient temperature (6 degrees C). Archiv Tieremahr, v.56, p.41-49, 2002b.

SAHIN, N.; ONDERCI, M.; SAHIN, K. Effects of dietary chromium and zinc on egg production, egg quality and some blood metabolites of laying hens reared under low ambient temperature. Biology Trace Elements Reserch, v.85, p.47-58, 2002c.

SAHIN, K.; SAHIN, N.; KUÇÜK, O. Effects of chromium, and ascorbic acid supplementation on growth, carcass traits, serum metabolites, and antioxidant status of broiler chickens reared at a high ambient temperature $\left(32^{\circ} \mathrm{C}\right)$. Nutrition Research, v.23, p.225-238, 2003.

TINOCO, I.F.F. Resfriamento adiabático evaporativo no controle térmico de galpões avícolas. In: CONFERÊNCIA APINCO DE CIÊnCIA E TECNOLOGIA, 1994, Campinas. Anais... Campinas: Associação Brasileira dos Produtores de Pintos de Corte, 1994. p.119.

UNIVERSIDADE FEDERAL DE VIÇOSA - UFV. Manual de Utilização do Programa SAEG (Sistema para Análises Estatísticas e Genéticas). Viçosa, MG: Central de Processamento de Dados (UFV/CPD), 1999. 59p.

VINCENT, J.B. The biochemistry of chromium. Journal of Nutrition, v.130, p.715-718, 2001

WILLIANS, D.A. A test for differences between treatments means when several dose levels are compared with a zero dose control. Biometrics, v.27, p.103-117, 1971.

Recebido: 18/01/06 Aprovado: 04/12/06 